\title{
Smoking, carbon monoxide, and atherosclerotic diseases
}

\author{
M HELIÖVAARA, M J KARVONEN, R VILHUNEN, S PUNSAR
}

British Medical fournal, 1978, 1, 268-270

\section{Summary and conclusions}

Smoking habits and random measurements of the proportion of haemoglobin bound to carbon monoxide (COHb\%) were examined for their association with atherosclerotic diseases in 1068 men aged 55 to 74 years from rural areas of Finland. COHb\% and smoking history were similarly associated with claudication and coronary heart disease. Random measurements of COHb\% did not show a better overall relation to the prevalence of atherosclerotic diseases than smoking history, though $\mathrm{COHb} \%$ showed a stronger association with a probable previous myocardial infarction. Further studies are needed to clarify the role of carbon monoxide in atherosclerosis.

\section{Introduction}

Cigarette smoking is a known risk factor for atherosclerotic disease. Exposure to cigarette smoke has generally been estimated by interview techniques, the information being based on the amount of tobacco smoked daily. The risk of atherosclerosis, however, is probably related more to the amount of smoke inhaled than to the number of cigarettes smoked, but it is difficult to evaluate the depth of inhalation with interview methods. ${ }^{1}$ Carbon monoxide constitutes about $4^{\circ}{ }_{0}$ of tobacco smoke and binds with haemoglobin to form a stable compound. Thus the proportion of haemoglobin bound to carbon monoxide $(\mathrm{COHb} \%)$ should be a good indicator of the depth of inhalation.

We decided to evaluate random estimations of $\mathrm{COHb}_{\%}$ in a study of the prevalence of atherosclerotic disease. We also looked for a possible independent association between $\mathrm{COHb}$ and atherosclerotic disease.

\section{Subjects and methods}

In 1959, 1711 men aged 40-59 years from rural areas of eastern and south-west Finland were enrolled in a cohort study of coronary heart disease (CHD) and other atherosclerotic diseases. ${ }^{2}$ In 1974, $1178(96.2 \%$ of the survivors) were re-examined, and $\mathrm{COHb}$ measurements were available for 1068 (522 from east Finland, and 546 from west Finland).

The men attended for examination between $8 \mathrm{am}$ and $2 \mathrm{pm}$. Venous blood samples were taken within half an hour of arrival. No instructions had been given about smoking before attendance, but subjects were not allowed to smoke while awaiting examination. Smoking on the day of examination was not recorded. $\mathrm{COHb} \%$ was

\footnotetext{
University of Helsinki, Department of Public Health Science, Helsinki, Finland

M HELIÖVAARA, MD, research assistant (present address: Research Institute for Social Security, Olavinkatu 1 B, SF-00100, Helsinki 10)

Finnish Heart Association, Helsinki

M J KARVONEN, MD, PHD, Surgeon General of the Defence Forces $S$ PUNSAR, MD, research assistant

Institute of Occupational Health, Helsinki

R VILHUNEN, MSC(ENG), head of biochemistry laboratory
}

estimated with a special spectrophotometer (182 CO-Oximeter, Instru- $\overrightarrow{\overline{\vec{\omega}}}$ mentation Laboratory Inc). Methods used to obtain clinical and other $\bar{C}$ data as well as data on smoking habits and serum cholesterol con- $\bar{\sigma}$ centrations have been described elsewhere. ${ }^{23}$ All clinical data were $\overline{\bar{c}}$ evaluated centrally and classified according to set rules.

Subjects were classified as having "definite" CHD when, in the absence of other heart disease (rheumatic, pulmonary, etc), there was a history of angina on effort or of a typical chest-pain attack of at $\vec{\circ}$ least half an hour's duration ${ }^{4}$ or when a resting electrocardiogram (ECG) showed Minnesota code ${ }^{5}$ changes of infarction (code I, 1-3); $\vec{\omega}$ ischaemic ST waves (IV, 1-3); negative $\mathrm{T}$ waves $(\mathrm{V}, 1,2)$; abnormal $\mathrm{S}$ atrioventricular or ventricular conduction (VI, 1, 2, 4; VII, 1, 2, 4); 윽 or atrial fibrillation. Two separate criteria were used to form subgroups of men with myocardial infarction-namely, a history of $\overrightarrow{-}$ typical chest-pain attack (with or without ECG abnormalities at $\vec{P}$ survey) and Minnesota code ECG changes I, 1, or I, 2 and V, 1, 2. A standard questionnaire was used ${ }^{4}$ to diagnose intermittent claudica- i tion, and the usual clinical criteria were used to diagnose stroke. Men $\infty$ with other types of heart disease; those with less definite symptoms 을 or signs of CHD, claudication, or cerebrovascular disease ; and those on whom data were incomplete were grouped separately. In the analyses of each disease manifestation in relation to smoking and $\mathbb{D}$ $\mathrm{COHb}$ the unaffected men only served as controls.

The subjects were primarily divided into eight subgroups (two areas, four five-year age groups in each). The following categories were used for history of smoking: never smoked, stopped smoking, current smokers $(1-9,10-19$, or 20 or more cigarettes a day), and pipe or cigar smokers (no cigarettes).

Partial correlation analysis was used to study the possibility that $\mathrm{COHb} \%$ was independently associated with atherosclerotic disease. We chose this statistical procedure to avoid spurious results due to the strong association of the explanatory variables, cigarette consumption and $\mathrm{COHb} \%$. Categories were used for both cigarette consumption (as above) and $\mathrm{COHb}_{0} \%(\leqslant 0.5 \% ; 0.6-2.0 \% ; \geqslant 2.1 \%)$. Thus the correlation coefficients indicate rank correlations between variables.

\section{Results}

Altogether $219(42 \%)$ of the men from east Finland (EF) and $164(30 \%)$ from west Finland (WF) were current smokers. The mean $\mathrm{COHb}$ concentration was $1.9 \%$ in east Finnish subjects and $1.7 \%$ in those from west Finland. The prevalence of definite atherosclerotic disease was higher in $\mathrm{EF}$ than in WF-claudication: $\mathrm{EF} 10 \%$, WF $6 \%$; stroke: EF $5 \%$, WF $3 \%$; CHD: EF $39 \%$, WF $28 \%$. The eight age- and area-specific subgroups and the total groups showed similarities in the association of atherosclerotic disease with smoking and $N$ $\mathrm{COHb} \%$; the results presented here are for the total groups only.

$\mathrm{COHb} \%$ was strongly related to smoking. There were few differences between those who had never smoked and those who had stopped smoking in their distribution according to $\mathrm{COHb} \%$ (table I). COHb $\mathrm{N}$ concentrations above $2 \%$ were much more common in current smokers than in the other men. The prevalence of claudication was greater among current and former smokers than in those who had never smoked (table II). $\mathrm{COHb}$ concentrations above $2 \%$ were associated with an increased prevalence of claudication (table III). On partial correlation analysis the correlation between $\mathrm{COHb} \%$ and claudication was low $(r=0.16 ; P<0.001)$. When the effect of cigarette smoking was eliminated the coefficient was reduced by half $(\mathrm{r}=0.08$; NS). The prevalence of stroke was inversely associated both with cigarette smoking and with $\mathrm{COHb} \%$ (tables II and III). Nevertheless, only 38 of the men had a history of stroke, and the associations were not significant.

There was a weakly positive association between the prevalence of definite CHD and cigarette smoking, and between CHD and $\mathrm{COHb} \%$; the association was significant $(\mathrm{P}<0.05)$, however, only for $\mathrm{COHb} \%$ (tables II and III). On partial correlation analysis $\rightleftharpoons$ $\mathrm{COHb} \%$ was not correlated with CHD when the influence of cigarette smoking on the correlation coefficient was eliminated. Similarly the occurrence of angina pectoris was weakly associated with both smoking 
and $\mathrm{COHb} \%$; the associations tended to be significant for both (tables II and III). Smoking was not associated with a history of an attack of chest pain or with ECG signs of myocardial infarction (table II). Nevertheless, attacks of chest pain occurred at least twice as often in men with $\mathrm{COHb}$ concentrations above $0.5 \%$ compared with those with $\mathrm{COHb}$ concentrations of $0.5 \%$ or less (table III). The correlation between the $\mathrm{COHb} \%$ and the occurrence of attacks was low $(\mathrm{r}=$ $0.13 ; \mathrm{P}<0.001)$. The correlation coefficient remained unchanged $(r=0 \cdot 13)$ on partial correlation analysis after eliminating the influence of smoking.

When studied separately in the three groups according to cigarettesmoking habit, the association of chest-pain attacks with raised $\mathrm{COHb} \%$ was particularly clear in the ex-smokers (table IV). ECG signs of myocardial infarction tended to be associated with $\mathrm{COHb}$ concentrations above $0.5 \%$ (table III), but the numbers were small and the associations were not significant.

Systolic blood pressure was inversely correlated with cigarette consumption $(\mathrm{r}=-0.14 ; \mathrm{P}<0.001)$. The correlation with $\mathrm{COHb} \%$ was not significant $(r=-0.06)$. Serum cholesterol concentration was not correlated with cigarette consumption or $\mathrm{COHb} \%$. The associations between atherosclerotic disease and smoking and $\mathrm{COHb} \%$ were also studied separately in three subgroups according to blood pressure and serum cholesterol concentration-namely, systolic blood pressure $<141,141-160,>160 \mathrm{~mm} \mathrm{Hg}$; serum cholesterol $<5 \cdot 8 \mathrm{mmol} / \mathrm{l}(<226 \mathrm{mg} / 100 \mathrm{ml}), 5 \cdot 8-7 \cdot 1 \mathrm{mmol} / \mathrm{l}(226-275 \mathrm{mg} / 100 \mathrm{ml})$, $>7.1 \mathrm{mmol} / 1 \quad(>275 \mathrm{mg} / 100 \mathrm{ml})$-and were found to be similar. Hence the associations did not seem to be mediated by these two risk factors.

\section{Discussion}

Wald et al, ${ }^{6}$ who studied a group of 950 men and women aged 30-69, found that the prevalence of atherosclerotic disease correlated more with $\mathrm{COHb}$ concentrations than with smoking history. In our study randomly estimated $\mathrm{COHb}$ concentrations and cigarette consumption assessed by interview were similarly associated with the prevalence of atherosclerotic manifestations. Nevertheless, a history of an attack of chest pain was related more to $\mathrm{COHb} \%$ than to smoking history. Wald et al excluded men with more than one hour between smoking and venesection. $\mathrm{The} \mathrm{COHb} \%$ may thus have indicated the carbon monoxide dose of the last cigarette rather than the effect of longer duration of exposure to $\mathrm{CO}$. In our study $\mathrm{COHb}$ measurements were

TABLE I-Distribution of men according to cigarette-smoking habit and COHb\% (pipe and cigar smokers excluded)

\begin{tabular}{|c|c|c|c|c|c|c|c|c|c|c|c|c|}
\hline & & & \multicolumn{10}{|c|}{$\mathrm{COHb} \%$} \\
\hline & & & 0 & $0 \cdot 1-$ & $1 \cdot 1-$ & $2 \cdot 1-$ & $3 \cdot 1-$ & $4 \cdot 1-$ & $5 \cdot 1-$ & $6 \cdot 1-$ & $7 \cdot 1-$ & $\geqslant 8 \cdot 1$ \\
\hline $\begin{array}{l}\text { No }(\%) \text { who never smoked } \\
\text { No }(\%) \text { who had stopped smoking } \\
\text { No }(\%) \text { of current smokers }\end{array}$ & $\begin{array}{l}\cdots \\
\cdots\end{array}$ & $\begin{array}{l}\cdots \\
\cdots\end{array}$ & $\begin{array}{r}87(41 \cdot 4) \\
189(40 \cdot 3) \\
23(6 \cdot 4)\end{array}$ & $\begin{array}{c}55(26 \cdot 2) \\
131(27 \cdot 9) \\
34(9 \cdot 5)\end{array}$ & $\begin{array}{r}53(25 \cdot 2) \\
101(21 \cdot 5) \\
51(14 \cdot 2)\end{array}$ & $\begin{array}{l}6(2 \cdot 9) \\
29(6 \cdot 2) \\
49(13 \cdot 7)\end{array}$ & $\begin{array}{c}7(3 \cdot 3) \\
6(1 \cdot 3) \\
64(17 \cdot 8)\end{array}$ & $\begin{array}{c}1(0 \cdot 5) \\
9(1 \cdot 9) \\
60(16 \cdot 7)\end{array}$ & $\begin{array}{r}1(0 \cdot 5) \\
1(0 \cdot 2) \\
34(9 \cdot 5)\end{array}$ & $\begin{array}{r}1(0 \cdot 2) \\
20(5 \cdot 6)\end{array}$ & $\begin{array}{l}1(0 \cdot 2) \\
9(2 \cdot 5)\end{array}$ & $\begin{array}{r}1(0 \cdot 2) \\
15(4 \cdot 2)\end{array}$ \\
\hline
\end{tabular}

TABLE II-Occurrence ratios of atherosclerotic diseases according to smoking habits (numbers of definitely affected and unaffected men given in parentheses). Men only possibly affected together with five others on whom data on smoking habit were not available are excluded

\begin{tabular}{|c|c|c|c|c|c|c|c|c|}
\hline & & & \multirow{3}{*}{$\begin{array}{c}\text { Never } \\
\text { smoked }\end{array}$} & \multirow{3}{*}{$\begin{array}{l}\text { Stopped } \\
\text { smoking }\end{array}$} & \multicolumn{4}{|c|}{ Current smokers } \\
\hline & & & & & \multicolumn{3}{|c|}{ No of cigarettes/day } & \multirow{2}{*}{$\begin{array}{l}\text { Pipe or } \\
\text { cigar only }\end{array}$} \\
\hline & & & & & $1-9$ & $10-19$ & $\geqslant 20$ & \\
\hline $\begin{array}{llr}\text { Claudication } & \ldots & \ldots \\
\text { Stroke } & \ldots & \ldots \\
\text { Definite CHD } & \ldots & \ldots \\
\text { Angina } & \ldots \\
\text { ECG evidence of } & \text { infarction } \\
\text { Chest-pain attack } & . .\end{array}$ & $\begin{array}{l}\because \\
\because \\
\because \\
\because\end{array}$ & $\begin{array}{l}\because \\
\because \\
\cdots \\
\cdots\end{array}$ & $\begin{array}{l}1 \cdot 0(4 ; 158) \\
1 \cdot 0(9 ; 187) \\
1 \cdot 0(61 ; 123) \\
1 \cdot 0(29 ; 123) \\
1 \cdot 0(8 ; 123) \\
1 \cdot 0(22 ; 123)\end{array}$ & $\begin{array}{l}3 \cdot 3^{*}(29 ; 329) \\
1 \cdot 0(19 ; 402) \\
1 \cdot 1(151 ; 251) \\
1.5 *(102 ; 251) \\
1 \cdot 3(21 ; 251) \\
1.2(57 ; 251)\end{array}$ & $\begin{array}{l}9 \cdot 7^{* * *}(16 ; 51) \\
0 \cdot 3(1 ; 81) \\
1 \cdot 3(38 ; 48) \\
1 \cdot 7 *(23 ; 48) \\
1 \cdot 3(4 ; 48) \\
1 \cdot 2(11 ; 48)\end{array}$ & $\begin{array}{l}4.3 * *(10 ; 84) \\
0.9(5 ; 115) \\
1.2(50 ; 75) \\
1.5(31 ; 75) \\
0.8(4 ; 75) \\
1.3(19 ; 75)\end{array}$ & $\begin{array}{l}8.8 * * *(20 ; 72) \\
0.5(3 ; 127) \\
1.1(45 ; 82) \\
1.5(33 ; 82) \\
1.3(7 ; 82) \\
1.0(15 ; 82)\end{array}$ & $\begin{array}{l}8 \cdot 7 * * \dagger(3 ; 11) \\
0(0 ; 23) \\
1.1(7 ; 12) \\
0.7(2 ; 12) \\
1.3(1 ; 12) \\
0.9(2 ; 12)\end{array}$ \\
\hline
\end{tabular}

${ }^{*} \mathrm{P}<0.05 ; * * \mathrm{P}<0.01 ; * * \mathrm{P}<0.001\left(\chi^{2}\right.$ test $)$

†Fisher's exact test.

TABLE III-Occurrence ratios of atherosclerotic diseases according to COHb\% (numbers of definitely affected and unaffected men given in parentheses). Men only possibly affected are excluded

\begin{tabular}{|c|c|c|c|c|c|c|c|}
\hline & & & & \multicolumn{4}{|c|}{$\mathrm{COHb} \%$} \\
\hline & & & & $\leqslant 0.5$ & $0 \cdot 6-2 \cdot 0$ & $2 \cdot 1-4 \cdot 0$ & $>4.0$ \\
\hline 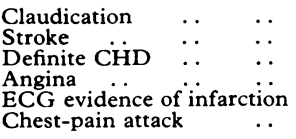 & $\begin{array}{l}\cdots \\
\cdots \\
\cdots \\
\cdots \\
\cdots\end{array}$ & $\begin{array}{l}\cdots \\
\cdots \\
\cdots \\
\cdots\end{array}$ & $\begin{array}{l}\ldots \\
\cdots \\
\cdots \\
\cdots \\
\cdots\end{array}$ & $\begin{array}{l}1 \cdot 0(17 ; 283) \\
1 \cdot 0(20 ; 357) \\
1 \cdot 0(108 ; 237) \\
1 \cdot 0(66 ; 237) \\
1 \cdot 0(12 ; 237) \\
1 \cdot 0(27 ; 237)\end{array}$ & $\begin{array}{l}1 \cdot 4(20 ; 235) \\
0 \cdot 7(11 ; 284) \\
1 \cdot 3^{*}(118 ; 182) \\
1 \cdot 3(74 ; 182) \\
1 \cdot 8(17 ; 182) \\
2 \cdot 1^{* * *}(49 ; 182)\end{array}$ & $\begin{array}{l}2 \cdot 3^{* *}(16 ; 105) \\
0 \cdot 5(4 ; 149) \\
1 \cdot 3 *(66 ; 91) \\
1 \cdot 5^{*}(43 ; 91) \\
2 \cdot 1(10 ; 91) \\
2 \cdot 0^{* *}(24 ; 91)\end{array}$ & $\begin{array}{l}4 \cdot 5^{* * *}(29 ; 84) \\
0 \cdot 4(3 ; 146) \\
1 \cdot 3^{*}(62 ; 86) \\
1 \cdot 4^{*}(39 ; 86) \\
1 \cdot 4(6 ; 86) \\
2 \cdot 4^{* * *}(28 ; 86)\end{array}$ \\
\hline
\end{tabular}

${ }^{*} \mathrm{P}<0.05 ; * * \mathrm{P}<0.01 ; * * \mathrm{P}<0.001\left(\chi^{2}\right.$ test $)$.

TABLE IV-Association of previous chest-pain attack with COHb\% according to cigarette-smoking habit (pipe and cigar smokers excluded)

\begin{tabular}{|c|c|c|c|c|c|c|c|c|c|c|}
\hline \multirow{2}{*}{\multicolumn{2}{|c|}{$\mathrm{COHb} \%:$}} & \multicolumn{3}{|c|}{ No attack } & \multicolumn{3}{|c|}{ Attack } & \multirow[b]{2}{*}{$\mathrm{DF}$} & \multirow[b]{2}{*}{$x^{2}$} & \multirow[b]{2}{*}{$\mathbf{P}$} \\
\hline & & $\leqslant 0.5$ & $0.6-2 \cdot 0$ & $\geqslant 2 \cdot 1$ & $\leqslant 0 \cdot 5$ & $0 \cdot 6-2 \cdot 0$ & $\geqslant 2 \cdot 1$ & & & \\
\hline $\begin{array}{l}\text { No }(\%) \text { who never smoked } \\
\text { No }(\%) \text { who had stopped smoking } \\
\text { No }(\%) \text { of current smokers } \quad . .\end{array}$ & $\begin{array}{l}\cdots \\
\cdots\end{array}$ & $\begin{array}{r}105(55 \cdot 9) \\
232(56 \cdot 3) \\
38(12 \cdot 1)\end{array}$ & $\begin{array}{r}69(36 \cdot 7) \\
143(34 \cdot 7) \\
63(20 \cdot 1)\end{array}$ & $\begin{aligned} 14(7 \cdot 5) \\
37(9 \cdot 0) \\
213(67 \cdot 8)\end{aligned}$ & $\begin{array}{l}10(45 \cdot 5) \\
15(26 \cdot 3)\end{array}$ & $\begin{array}{l}11(50 \cdot 0) \\
31(54 \cdot 4) \\
7(15 \cdot 6)\end{array}$ & $\begin{array}{l}1(4 \cdot 6) \\
11(19 \cdot 3) \\
38(84 \cdot 4)\end{array}$ & $\begin{array}{l}2 \\
2 \\
2\end{array}$ & $\begin{array}{r}1 \cdot 54 \\
18 \cdot 99 \\
7 \cdot 41\end{array}$ & $\begin{array}{l}\text { NS } \\
<0.001 \\
<0.05\end{array}$ \\
\hline
\end{tabular}

Analysis by groups including COHb concentrations $\leqslant 2 \cdot 0 \%$ only-Never smoked: $\chi^{2}=1 \cdot 25 ; \mathrm{DF}=1 ; \mathrm{NS}$. Stopped smoking: $\chi^{2}=14 \cdot 46 ; \mathrm{DF}=1 ; \mathrm{P}<0 \cdot 001$. Current smokers (Fisher's exact test): $z=1 \cdot 60$; NS. 
made at random, which gives a good indication of the mean $\mathrm{COHb}$ concentration in smokers. ${ }^{\text {? }}$

A history of an attack of chest pain suggesting myocardial infarction was associated with raised $\mathrm{COHb}$ concentrations; a similar relation was not found for smoking history. The association was unlikely to have been caused by greater frequency of "false" attacks of chest pain in men with raised $\mathrm{COHb}$ concentrations because a similar association was found for ECG signs of myocardial infarction. The association was mainly caused by slight rises in $\mathrm{COHb}$ concentration $\left(0 \cdot 6-2 \cdot 0^{\circ}{ }_{0}\right)$. The finding of this association among ex-smokers was unexpected; occasional smokers who had already had a myocardial infarction may have denied their habit more often than the other men.

Because our subjects were middle-aged and older men from rural areas, we cannot make generalised conclusions. Furthermore, a cross-sectional study such as this has sources of bias: for instance, the men who had diseases associated with smoking may have altered their smoking habits. A prospective population study is needed to clarify the role of carbon monoxide in atherosclerosis.

\section{References}

1 Wald, N, et al, Thorax, 1975, 30, 133.

${ }^{2}$ Karvonen, M J, et al, Acta Medica Scandinavica, 1967, Suppl No 460, $\overrightarrow{\overline{\vec{N}}}$

p 169.
${ }^{3}$ Karvonen, M J, et al, American Heart Association Monograph No 29 , 은

1970, p 52 .
${ }^{4}$ Rose, G A, and Blackburn, H, Cardiovascular Survey Methods, Monograph No 56. Geneva, World Health Organisation, 1968.

${ }^{5}$ Blackburn, H, et al, Circulation, 1960, 21, 1160.

${ }^{6}$ Wald, N, et al, British Medical fournal, 1973, 1, 761.

${ }^{7}$ Castleden, C M, and Cole, P V, British Medical fournal, 1974, 4, 736

(Accepted 15 November 1977)

\title{
Influence of induced abortion on gestational duration in subsequent pregnancies
}

\author{
J W VAN DER SLIKKE, P E TREFFERS
}

British Medical fournal, 1978, 1, 270-272

\section{Summary and conclusions}

We studied the effect of previous induced and spontaneous abortion on gestational duration in subsequent pregnancies in 12 obstetric departments in the Netherlands. Only primiparae were studied. Of 504 women who had had a previous induced abortion, $18(3.6 \%)$ delivered before 32 weeks' gestational age. Forty of 1313 women with a history of spontaneous abortion (3.0\%) and 259 of 12678 women with no history of abortion (2.1\%) also delivered before 32 weeks. The differences between the three groups were not significant.

In the Netherlands there are no significant indications that spontaneous midtrimester abortions or premature deliveries are caused by a previous induced abortion.

\section{Introduction}

Should women who have had induced abortions be afraid of additional risk in subsequent, wanted pregnancies ? English ${ }^{1-3}$ and eastern European ${ }^{4-7}$ studies show increased numbers of second-trimester spontaneous abortions and premature deliveries in women becoming pregnant after induced abortions. We aimed to evaluate the risks of such complications in Dutch women.

Since 1967 induced abortions have become more common in the Netherlands. In 1972-3 the estimated number of abortions was $20000-30000,{ }^{8}$ decreasing to $16000-18000$ in 1974 , and 15000 in $1975 . .^{910}$ This last figure gives a rate of approximately 5.5 abortions per 1000 women aged $15-44$ years, or 81 per 1000

\footnotetext{
Department of Obstetrics and Gynaecology, Wilhelmina Gasthuis, University of Amsterdam, The Netherlands

J W VAN DER SLIKKE, MD, senior resident

P E TREFFERS, MD, senior lecturer
}

births. Not more than $5^{\circ}{ }_{0}$ of abortions are induced beyond $12 \stackrel{0}{\circ}$ weeks' gestation, and $95^{\circ}$ of all interventions are performed by minimal dilatation and vacuum aspiration.

\section{Patients and methods}

The analysis was carried out in the department of obstetrics, $\overrightarrow{\vec{B}}$ Wilhelmina Gasthuis, University of Amsterdam. From January 1972 to June 1976 we reviewed 3780 primiparae admitted to this department who delivered at 17 weeks' gestation or more. Of these women, 265 त् $(7.0 \%)$ had had at least one previous induced abortion (group A). The second group consisted of 348 primiparae $(9.2 \%)$ who had had at least one spontaneous abortion and no induced abortions (group B). A third group of 3167 women $(83.8 \%$ ) had had no abortions (group E).

Age-matched controls were selected for each woman in groups A and $\mathrm{B}$ from primiparae delivering immediately afterwards who had no history of abortion (groups $\mathrm{C}$ and $\mathrm{D}$ ). We compared gestational age at delivery between these four groups and between groups $A, B$, $O$ and $\mathrm{E}$. When the date of the last menstrual period was not exactly known, gestational age was estimated from information on prenatal o care, birth weight, and Dubowitz score.

In addition to the material from our own department, we had at our disposal data kindly supplied by GVR (Gemeenschappelijke $\mathrm{N}$ Verloskundige Registratie-that is, Co-operative Obstetric Registra- O tion). In this register, data are collected from 11 obstetric departments $\omega$ in various regions of the Netherlands. ${ }^{11}$ By adding these data to our own, we could study material from 12 departments. From this we 0 selected only primiparae for whom gestational age of pregnancy was known. We excluded women with multiple pregnancies and those who had undergone conisation of the cervix or had uterine scars or congenital malformations of the uterus.

Thus our total series included 14495 primiparae, of whom 12678 had no history of abortion $(87.5 \%), 504$ had had a previous induced abortion $(3.4 \%)$, and 1313 a spontaneous abortion $(9.1 \%)$. We compared gestational age at delivery in these larger groups.

\section{Results}

Table I shows gestational age at delivery in group $\mathrm{A}$ and its matched controls (C) and group B and its matched controls (D). In group A (previous induced abortion) the proportion of deliveries before 32 